\title{
OPEN Neuroanatomy of the nodosaurid Struthiosaurus austriacus (Dinosauria: Thyreophora) supports potential ecological differentiations within Ankylosauria
}

Marco Schade ${ }^{1,2,3 凶}$, Sebastian Stumpf ${ }^{4}$, Jürgen Kriwet ${ }^{4}$, Christoph Kettler ${ }^{5}$ \& Cathrin Pfaff ${ }^{4 \bowtie}$

Nodosauridae is a group of thyreophoran dinosaurs characterized by a collar of prominent osteoderms. In comparison to its sister group, the often club-tailed ankylosaurids, a different lifestyle of nodosaurids could be assumed based on their neuroanatomy and weaponry, e.g., regarding applied defensive strategies. The holotype of the nodosaurid Struthiosaurus austriacus consists of a single partial braincase from the Late Cretaceous of Austria. Since neuroanatomy is considered to be associated with ecological tendencies, we created digital models of the braincase based on micro-CT data. The cranial endocast of $S$. austriacus generally resembles those of its relatives. A network of vascular canals surrounding the brain cavity further supports special thermoregulatory adaptations within Ankylosauria. The horizontal orientation of the lateral semicircular canal independently confirms previous appraisals of head posture for $S$. austriacus and, hence, strengthens the usage of the LSC as proxy for habitual head posture in fossil tetrapods. The short anterior and angular lateral semicircular canals, combined with the relatively shortest dinosaurian cochlear duct known so far and the lack of a floccular recess suggest a rather inert lifestyle without the necessity of sophisticated senses for equilibrium and hearing in S. austriacus. These observations agree with an animal that adapted to a comparatively inactive lifestyle with limited social interactions.

Thyreophora are ornithischian dinosaurs, comprising iconic taxa like Stegosaurus and Ankylosaurus ${ }^{1}$. Ankylosauria thrived at least since the Middle Jurassic and some of their representatives witnessed the end-Cretaceous mass extinction ${ }^{1}$. These globally distributed quadruped herbivores were heavily armoured living fortresses; partly either equipped with a club tail (ankylosaurids ${ }^{2}$ ) or a collar of hypertrophied spikes on their neck and shoulders (nodosaurids $^{3}$ ). Potential palaeoenvironmental ${ }^{4}$ and food preferences ${ }^{5}$, together with features of their nasal passages $^{6}$, jaw mechanics ${ }^{7,8}$ and osteoderms ${ }^{9}$, may indicate different lifestyles for both groups.

Since the brain and associated neuroanatomical structures of vertebrates leave perceivable traces, which are possibly ecologically informative, it is worthwhile to thoroughly examine the braincase of nodosaurids in order to compare it to ankylosaurids. Whereas complete braincase material among early-diverging thyreophorans is only known from Scelidosaurus harrisoni ${ }^{10}$, neurocranial material of stegosaurs ${ }^{11,12}$, and ankylosaurs (e.g. ${ }^{13-15}$ ) is more common. The heavily armored skull roofs of the latter likely improved their preservation potential.

Struthiosaurus is a European nodosaurid with an estimated body length of up to three metres, known from cranial and postcranial material of Campanian to Maastrichtian age ${ }^{16-22}$. As currently accepted, Struthiosaurus comprises three species: S. austriacus from the early Campanian of Austria ${ }^{16-18}$, S. languedocensis from the early Campanian of France ${ }^{22}$, and S. transylvanicus from the Maastrichtian of Romania ${ }^{23,24}$. In addition, skeletal remains referred to Struthiosaurus sp. were reported from late Campanian to early Maastrichtian deposits of

${ }^{1}$ Institute of Geography and Geology, Palaeontology and Historical Geology, University of Greifswald, 17489 Greifswald, Germany. ${ }^{2}$ Zoological Institute and Museum, Cytology and Evolutionary Biology, University of Greifswald, 17489 Greifswald, Germany. ${ }^{3}$ Department of Earth and Environmental Sciences, Palaeontology and Geobiology, Ludwig-Maximilians-Universität, 80333 Munich, Germany. ${ }^{4}$ Department of Palaeontology, Faculty of Earth Sciences, Geography and Astronomy, University of Vienna, 1090 Vienna, Austria. ${ }^{5}$ Department of Geology, Faculty of Earth Sciences, Geography and Astronomy, University of Vienna, 1090 Vienna, Austria. ${ }^{\boxplus}$ email: marco.schade@stud.uni-greifswald.de; cathrin.pfaff@univie.ac.at 
Spain $^{20,21}$. The potentially oldest fossil record of Struthiosaurus is represented by a single right humerus from the Santonian of Hungary ${ }^{25}$. The type species of Struthiosaurus, S. austriacus, is based on fragmentary cranial and postcranial remains of at least three individuals of different ontogenetic stages that were recovered during the nineteenth century from early Campanian continental coal-bearing beds of Muthmannsdorf, Austria, referred to the Grünbach Formation (see ${ }^{18}$ for overview).

The holotype specimen of S. austriacus, a partial braincase (IPUW 2349/6; Fig. 1), was scanned with the aid of a micro-CT; its superficial morphology has been previously described ${ }^{16,17,26}$. The segmentation of the internal structures provides new insights into the neuroanatomy and behavioral capacities of this Late Cretaceous (Campanian) armoured dinosaur from Austria.

\section{Results}

Cranial endocast, innervation and blood supply. As in most non-maniraptoriform dinosaur braincases $\left(\right.$ e.g. ${ }^{27-29}$ ), features of the midbrain and hindbrain are not securely identifiable as imprints on the endocast of IPUW 2349/6 (Figs. 2,3). This suggests little correlation of the brain and respective soft tissues with the surface of the endocranial cavity in the living animal, which is similar to extant reptiles (e.g., crocodiles and turtles ${ }^{30,31}$ ).

Although not completely preserved, the endocranial cavity suggests great angles of both the cerebral and the pontine flexure in IPUW 2349/6, matching the condition in other ankylosaurs and stegosaurs ${ }^{11-13,32}$. The endocast shows a slight dural peak (Fig. 2A), where the pineal gland would be expected, similar to the condition in the ankylosaur Kunbarrasaurus ieversi ${ }^{14}$. The presence of the cartilage-filled pit in the supraoccipital, expressed as an anteroventrally inclined ridge on the cranial endocasts of Struthiosaurus austriacus, $S$. transylvanicus ${ }^{17}$ and the nodosaurid Hungarosaurus sp. ${ }^{32}$, is barely discernable in the digital endocast of IPUW 2349/6. Ventral to the pineal, around the mid-height of the brain endocast, the dorsal middle cerebral vein could be reconstructed on the right side (Fig. 2E,F; vcm). Additionally, at least two large canals, tentatively assigned to the transversooccipital vein ${ }^{13}$, traverse each paroccipital process and the prootic mainly anteroposteriorly; without any obvious connection to another endocranial structure (Fig. 2A,C,E). More delicate and complex networks of canals are present further anterodorsally and may belong to the posterior branching plexus ${ }^{13}$. Possibly, the expanding mediolateral width of the anterodorsal endocast marks the otherwise barely delineated cerebral hemispheres. Anteroventrally, the posterior portion of the pituitary fossa is preserved, together with the ventrolaterally directed internal carotid artery (Fig. 3A,B; pit; ic). Around the preserved mid-length, each internal carotid artery branch is connected to another vascular duct of uncertain identity, leading in a posterodorsolateral direction. The canal for the abducens nerve (Fig. 3A,B; CN VI) is situated posterolaterally to the pituitary fossa. While the facial nerve opening (CN VII) is situated anteriorly to the cochlear duct, the columellar recess, the metotic foramen (for CN IX-XI and jugular vein) and the hypoglossal nerve openings (CN XII) are situated posterior to the cochlear duct. Due to the fact that the specimen is strongly traversed by breakages, the canals for CN VII and IX-XI likely appear slightly too large in our reconstruction, but certainly approximate the course of the respective canals. However, for the same reason, the exact position and course of the CN XII openings and canals could not be established with certainty, but are estimated on the basis of internal and external characteristics. The micro-CT data suggest the presence of two CN XII openings per side, which are largely obscured by cracks on the outside (Figs. 1J,K, 2E,F, 3C,D). While Pereda-Suberbiola and Galton ${ }^{16}$ identified two foramina on the left side of the specimen as the openings for CN XII, our reconstruction suggests that the more ventrally situated foramen actually represents the metotic foramen. In posterior view, medially to the left metotic foramen, another foramen seems to be situated (Fig. 1J,K) but the micro-CT data show that this is just a superficial damage. The midbrain of IPUW $2349 / 6$ does not possess a floccular recess. Posteriorly, the foramen magnum is connected to the mediolaterally wide medulla oblongata. The incomplete endocranial cavity comprises a volume of around $12 \mathrm{~cm}^{3}$ (measured according to Sampson and Witmer ${ }^{33}$ ).

Endosseous labyrinth. The vestibular system is ventrally connected to the cochlea and together they form the completely preserved endosseous labyrinth of IPUW 2349/6 (Fig. 4). The anterior semicircular canal is dorsoventrally slightly higher and anteroposteriorly wider than the posterior semicircular canal (Fig. 4A). The vertical semicircular canals are thick and short in relation to the complete vestibular system. In dorsal view, they enclose an angle of $91^{\circ}$ in the right vestibular system and $98^{\circ}$ at the left vestibular system. The common crus, uniting the anterior and posterior semicircular canal, is slightly posteriorly inclined. In dorsal view, the relatively thick lateral semicircular canal projects posterolaterally and arcs towards the posterior ampulla, producing a very acute angle on its distal-most corner (Fig. 4C). The cochlear duct is strikingly short on both sides, being dorsoventrally shorter than the vestibular system (Fig. 4E). The cochlear duct projects anteroventrolaterally and is strongly tapered distally.

Auditory capabilities. In order to very roughly estimate the auditory capability of $S$. austriacus, we digitally measured the dorsoventral cochlear duct length (c. $5.9 \mathrm{~mm}$; as outlined by Walsh et al. ${ }^{34}$ ) and the anteroposterior basicranial length (c. $40.5 \mathrm{~mm}$; measured between the anterior-most preserved part of the sella turcica and the distal-most part of the occipital condyle). Following the equations of Walsh et al. ${ }^{34}$, we calculate the mean hearing frequency of $S$. austriacus as $1230 \mathrm{~Hz}$ and the frequency bandwidth as $1868 \mathrm{~Hz}$ (between 296 and $2164 \mathrm{~Hz}$ ).

\section{Discussion}

Neurovascularanatomy and ecological affinities. The presence of widely distributed vascular canals in the holotypic neurocranium of Struthiosaurus austriacus adds to the diversity of patterns within Thyreophora ${ }^{6,13,14,35}$. Conversely to Bissektipelta archibaldi ${ }^{13}$, these canals are not obviously interconnected with each other or the cavity that once contained the brain, and are located closer to the endosseous labyrinth in $S$. 
A

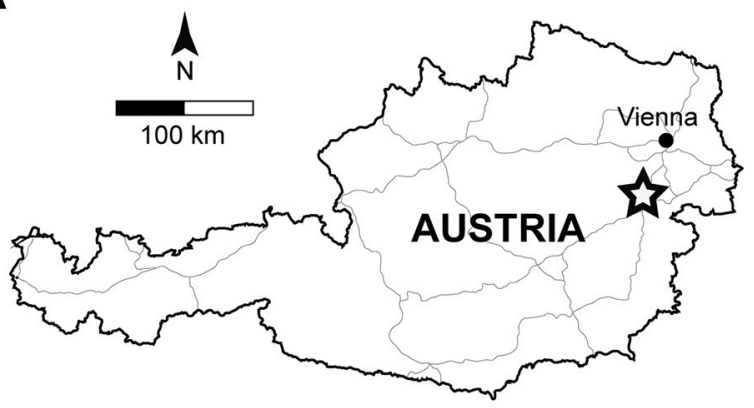

B

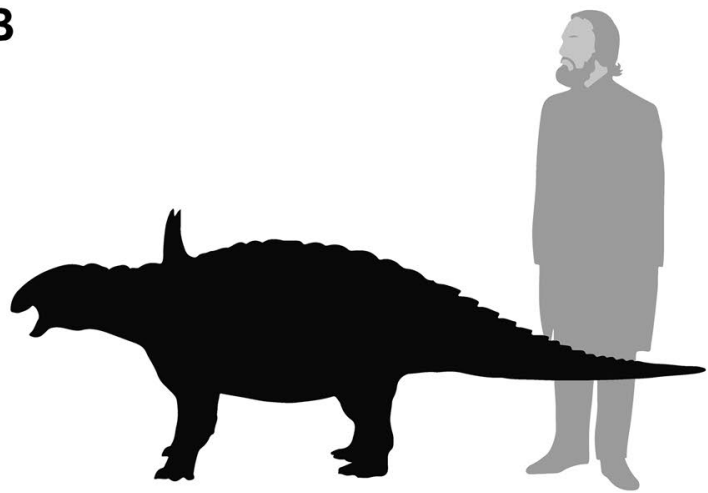

C

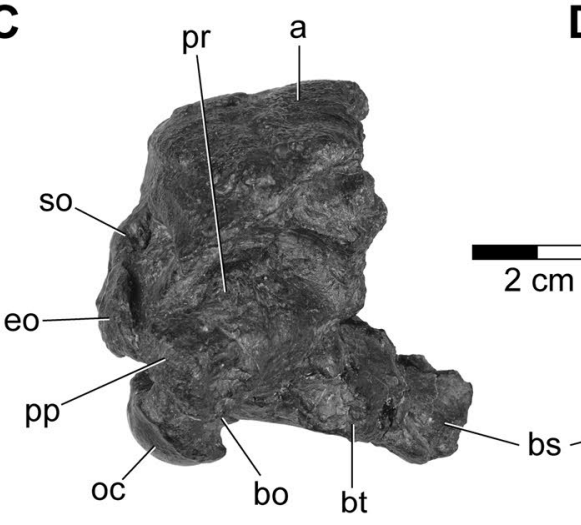

D<smiles>[Li][Mg]</smiles>
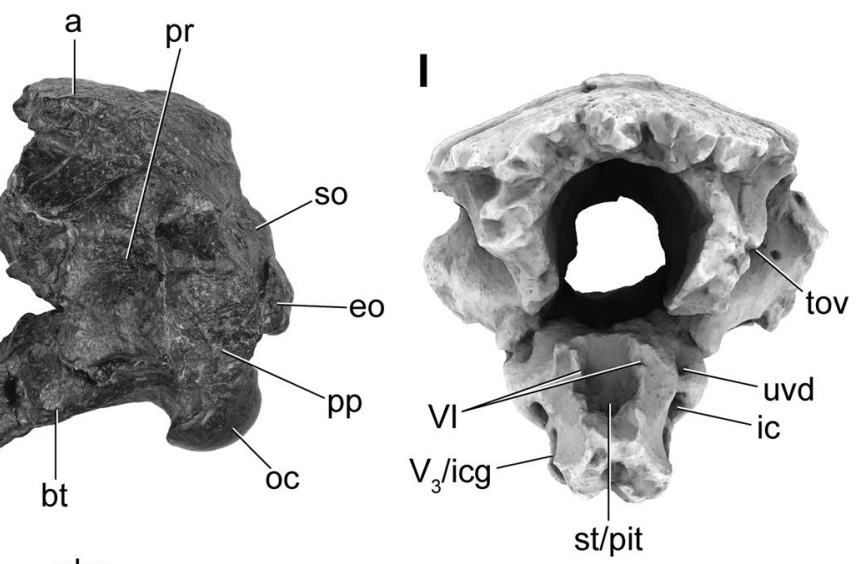

$\mathbf{E}$
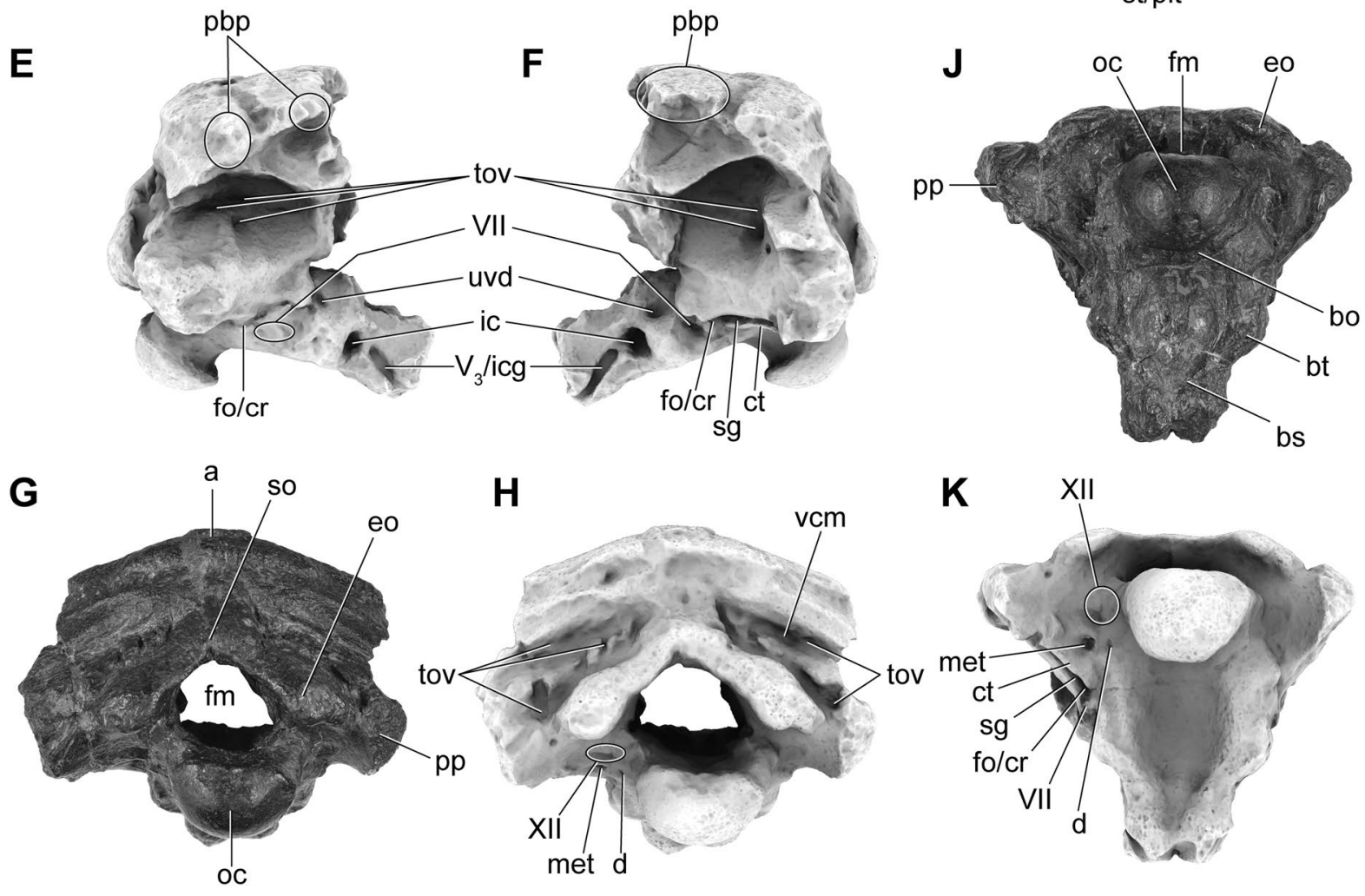

H
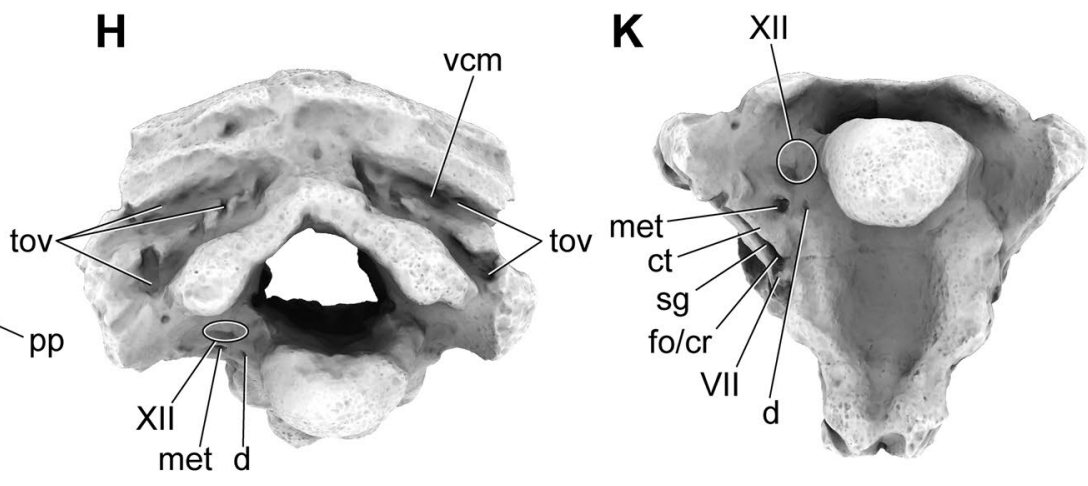

Figure 1. (A) Outline drawing of Austria with a star marking Muthmannsdorf, the type locality of Struthiosaurus austriacus. (B) Silhouette of Struthiosaurus austriacus (measuring $2.7 \mathrm{~m}$ in length here; copyright: Fabrizio De Rossi) and a human for comparison. Photographs $(\mathbf{C}, \mathbf{D}, \mathbf{G}, \mathbf{J})$ and ambient occlusion photogrammetric models $(\mathbf{E}, \mathbf{F}, \mathbf{H}, \mathbf{I}, \mathbf{K})$ of the holotype specimen of Struthiosaurus austriacus, IPUW 2349/6, in (C,E) right lateral, (D,F) left lateral, (I) anterior, (J,K) ventral and (G,H) posterior views. a, armour; bo, basioccipital; bs, basisphenoid; bt, basal tuber; ct, crista tuberalis; d, damage; fm, foramen magnum; fo/cr, fenestra ovalis/columellar recess; met, metotic foramen; pbp, posterior branching plexus; sg, stapedial groove; st/pit, sella turcica/pituitary; tov, transverso-occipital vein; uvd, uncertain vascular duct; $\mathrm{V}_{3} / \mathrm{icg}$, groove for the mandibular branch of the trigeminal nerve or for the internal carotid; VI, abducens nerve; VII, facial nerve; vcm, dorsal middle cerebral vein; XII, hypoglossal nerve. 
A

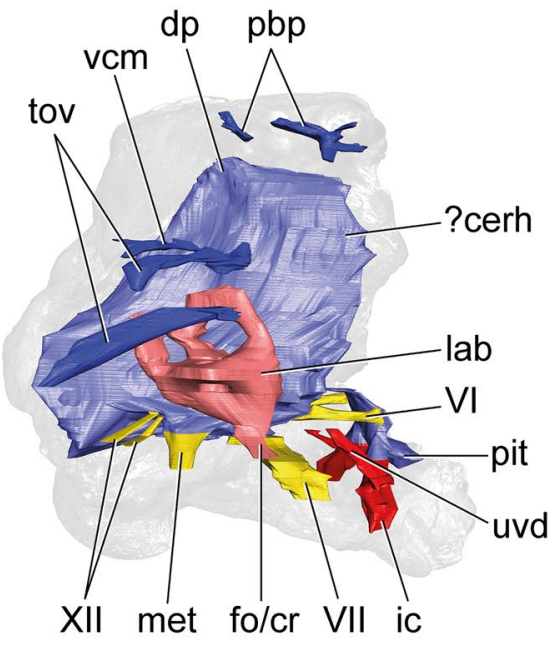

B

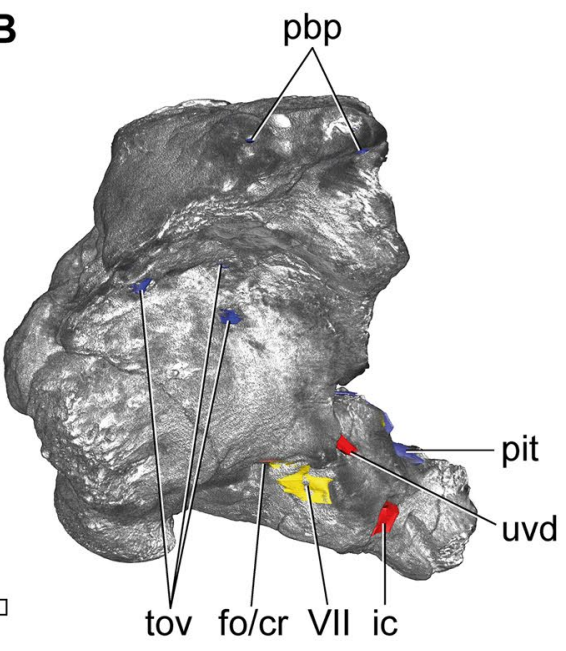

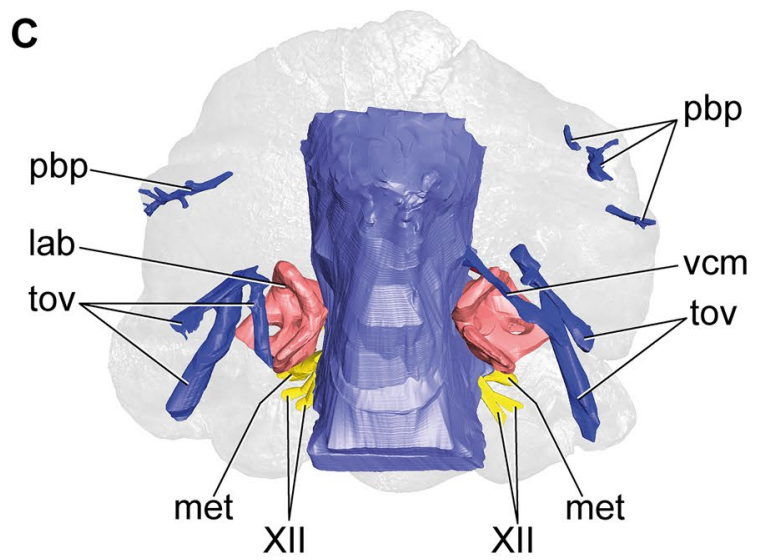

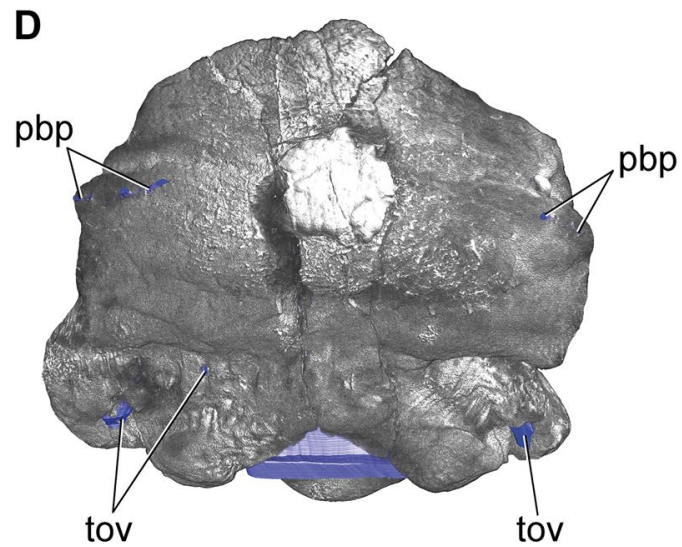

E

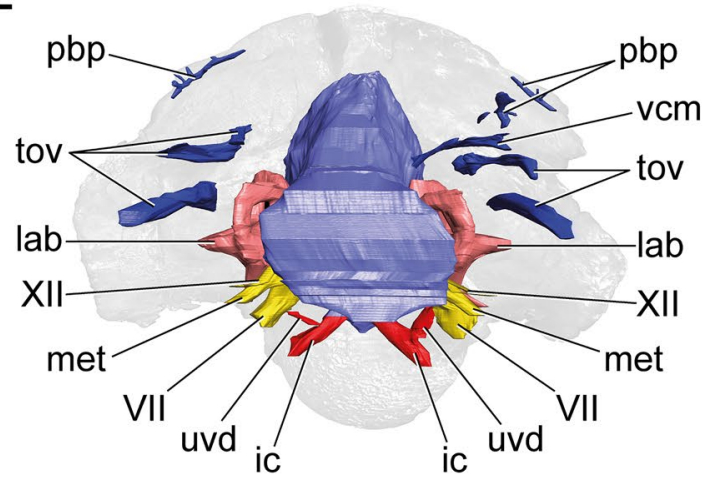

F

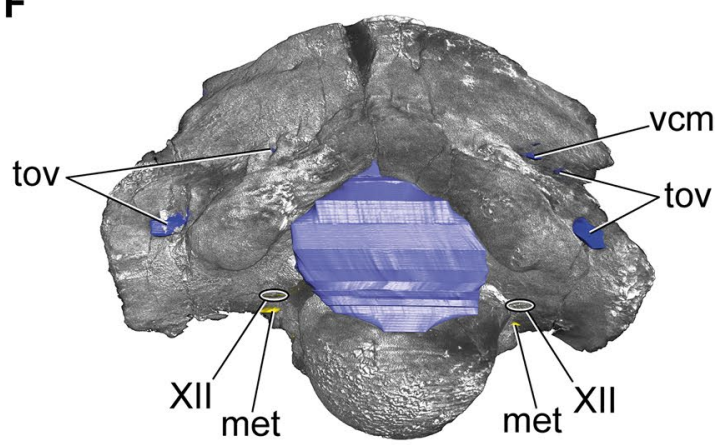

Figure 2. 3D model of the cranial endocast with endosseous labyrinths and neurovascular canals of the holotype specimen of Struthiosaurus austriacus, IPUW 2349/6, without (A,C,E) and with (B,D,F) a volume rendering of the braincase in $(\mathbf{A}, \mathbf{B})$ right lateral, $(\mathbf{C}, \mathbf{D})$ dorsal and $(\mathbf{E}, \mathbf{F})$ posterior aspects. ?cerh, possible cerebral hemisphere; dp, dural peak; fo/cr, fenestra ovalis/columellar recess; met, metotic foramen; lab, endosseous labyrinth; pbp, posterior branching plexus; pit, pituitary; tov, transverso-occipital vein; uvd, uncertain vascular duct; VI, abducens nerve; VII, facial nerve; $\mathrm{vcm}$, dorsal middle cerebral vein; XII, hypoglossal nerve.

austriacus. As other authors suggested ${ }^{6,13,35}$, a complex network of blood supply tissue within the braincase could have contributed to remodelling of skull bones and armour, and thermoregulation of the brain. Additionally, the posterodorsolaterally directed duct on each internal carotid artery branch found in S. austriacus likely played a role in thermoregulation ${ }^{35}$.

The endosseous labyrinth of vertebrates detects head movements, making it critical in gaze stabilization during locomotion (e.g. $\left.{ }^{36}\right)$. Currently, it is a matter of debate to what extent the morphology of the semicircular canals is a proxy for certain ecological affinities within Archosauromorpha ${ }^{37,38}$. Few endosseous labyrinths of 
A

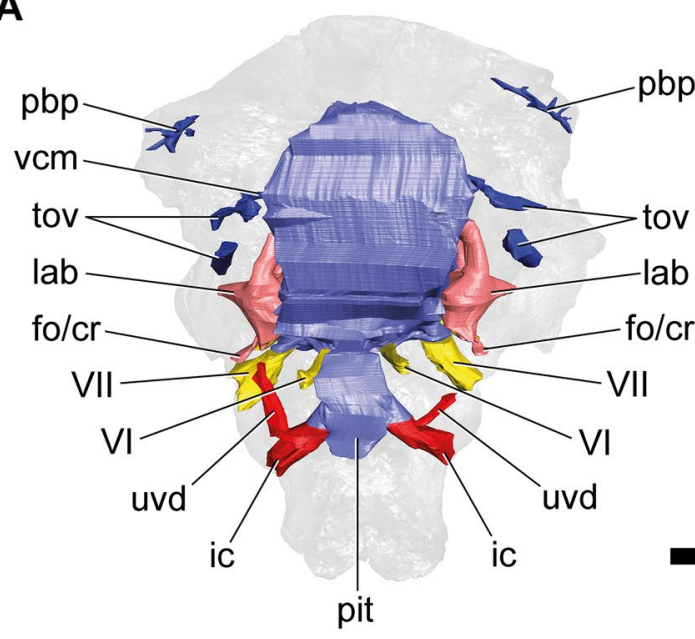

C

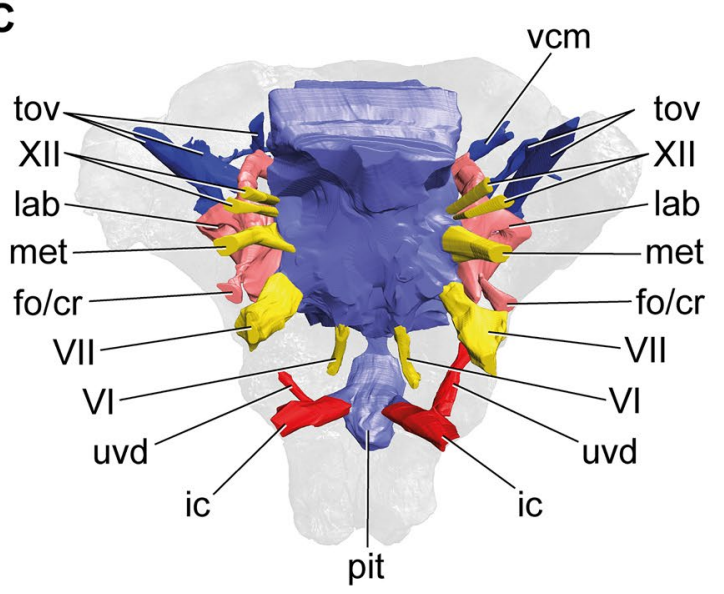

B

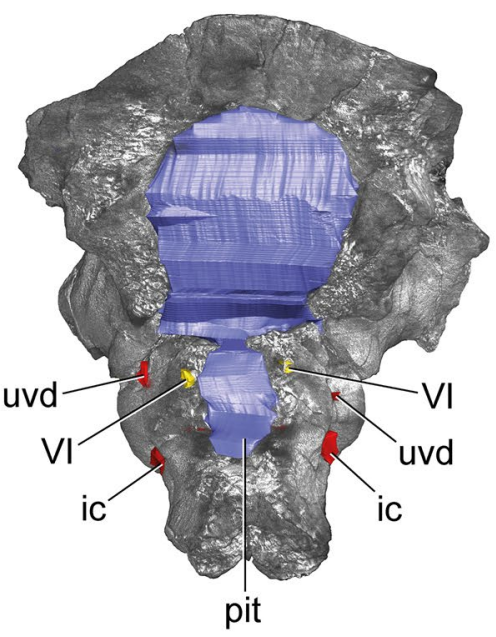

D

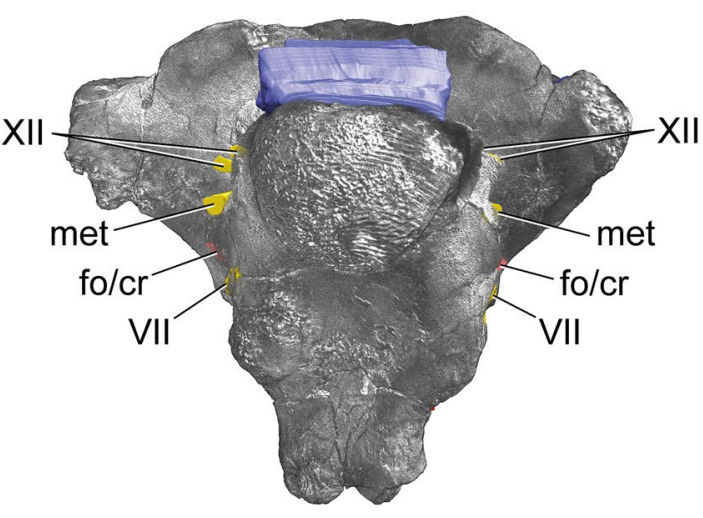

Figure 3. $3 \mathrm{D}$ model of the cranial endocast with endosseous labyrinths and neurovascular canals of the holotype specimen of Struthiosaurus austriacus, IPUW 2349/6 without (A,C) and with (B,D) a volume rendering of the braincase in $(\mathbf{A}, \mathbf{B})$ anterior and $(\mathbf{C}, \mathbf{D})$ ventral views. fo/cr, fenestra ovalis/columellar recess; met, metotic foramen; lab, endosseous labyrinth; pbp, posterior branching plexus; pit, pituitary; tov, transversooccipital vein; uvd, uncertain vascular duct; VI, abducens nerve; VII, facial nerve; vcm, dorsal middle cerebral vein; XII, hypoglossal nerve.

ankylosaur taxa are known, of which all possess relatively short and thick semicircular canals, as seen in the early-diverging ankylosaur Kunbarrasaurus ieversi ${ }^{14}$, the ankylosaurids B. archibald $i^{13}$, Euoplocephalus tutus ${ }^{39}$ (and probably T. teresae ${ }^{15}$ ), and the nodosaurid Pawpawsaurus campbelli ${ }^{40}$. Hence, including S. austriacus, only two nodosaurid endosseous labyrinths are known to date and both display an anterior semicircular canal, which is just slightly longer than the respective posterior semicircular canal. This contrasts the condition seen in $K$. ieversi ${ }^{14}, B$. archibaldi $i^{13}$ and $E$. $t u t u s^{39}$, clearly showing a relatively longer ASC. Long semicircular canals are thought to be more sensitive for head movements ${ }^{33}$, and hence potentially related to neck mobility ${ }^{41,42}$. The unique and conspicuously acute angle at mid-length of the lateral semicircular canal of $S$. austriacus did probably impede a continuous endolymphatic flow, causing insensitivity in comparison to the usual rounded condition. Furthermore, the combination of a longer ASC in two ankylosaurid taxa (B. archibaldi and E. tutus), as well as the presence of a floccular recess (E. tutus and T. teresae), may render ankylosaurids superior in VOR (vestibulo-ocular reflex) and VCR (vestibulo-collic reflex) procession in comparison to nodosaurids. This could be associated with a more active kind of protective behaviour in ankylosaurids, involving digging and targeting usage of their tail clubs $2,15,43,44$.

Because of its involvement in processing VOR/VCR, the flocculus is a critical structure of the cerebellum for control and coordination of head, eye, and neck movements ${ }^{41,45,46}$. Although the size of the floccular fossa has been found to fail as a proxy for ecology or behavior in certain extant mammals and birds ${ }^{47}$, it has repeatedly been used to tentatively establish such a meaning for fossil taxa (e.g. ${ }^{15,33,48}$ ). Additionally, ontogeny possibly plays a role in the expression of the flocculus on the endocast ${ }^{28}$. A lack of a floccular recess is common for ankylosaurs, except for a group within Ankylosaurinae $e^{13,15}$, and no floccular recess has been found in any nodosaurid endocast so far ${ }^{32,40}$. However, a floccular recess is present in the ankylosaurine ankylosaurids E. tutus $s^{14,39}$ and T. teresae $e^{40}$. Furthermore, braincase endocasts of the stegosauruids Stegosaurus ${ }^{11}$ and Kentrosaurus ${ }^{12}$ share slight lateral 
A

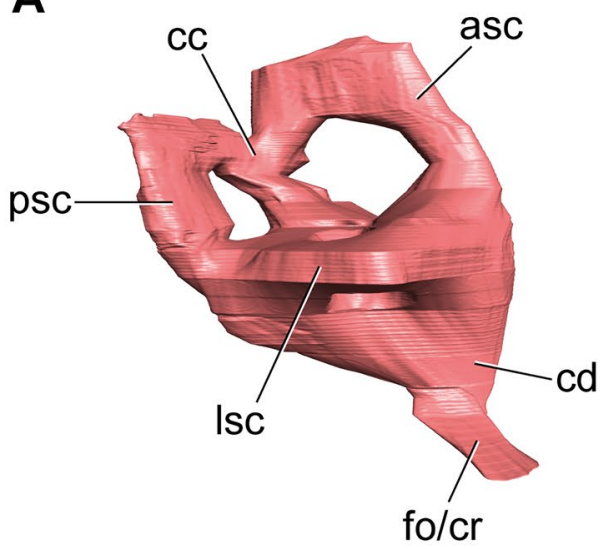

B

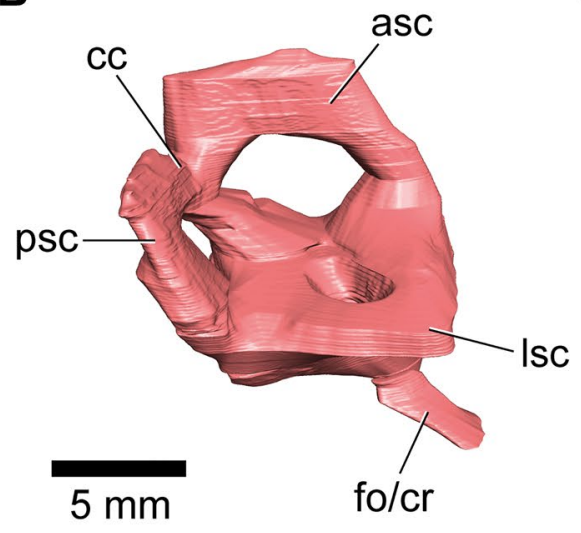

C

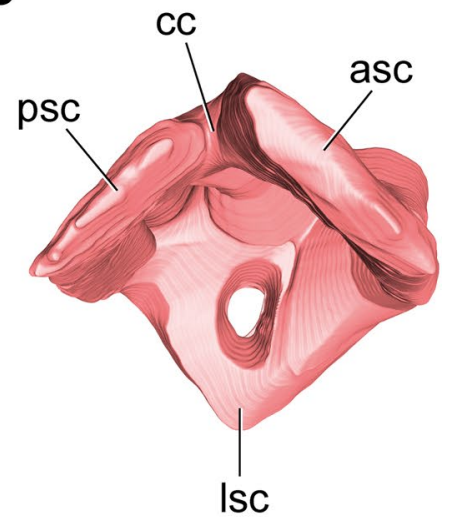

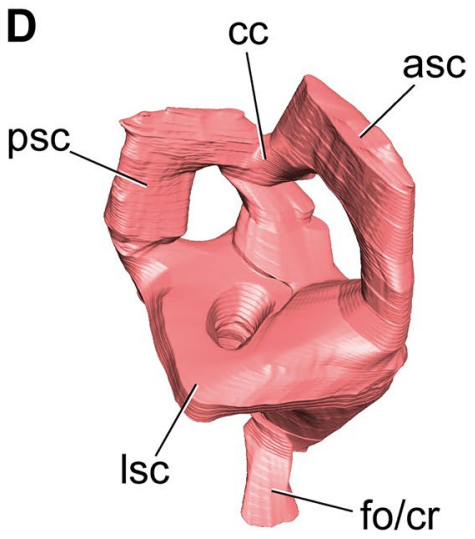

E

F

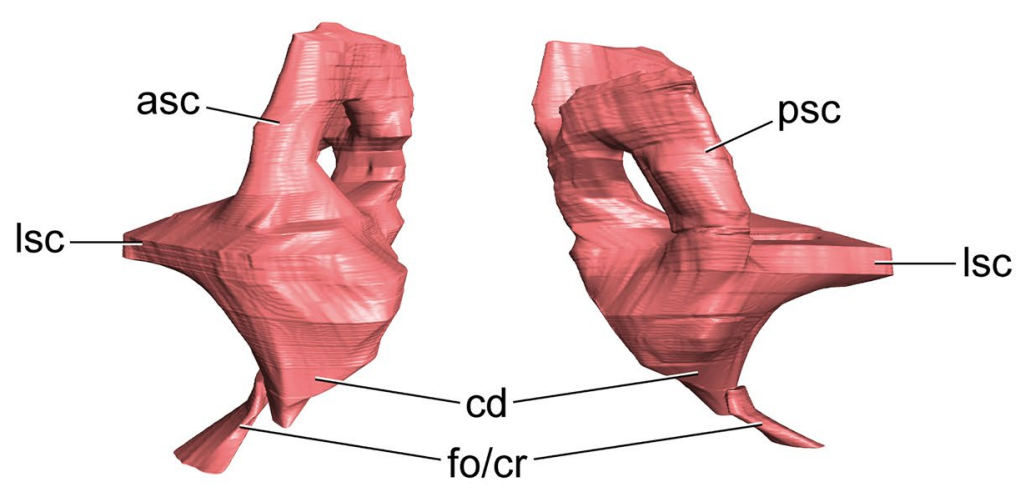

Figure 4. 3D model of the right endosseous labyrinth of the holotype specimen of Struthiosaurus austriacus, IPUW 2349/6, in (A) lateral, (B) posterodorsolateral, (C) dorsal, (D) anterodorsolateral, (E) anterior and (F) posterior views. asc, anterior semicircular canal; cc, common crus; cd, cochlear duct; fo/cr, fenestra ovalis/ columellar recess; lsc, lateral semicircular canal; psc, posterior semicircular canal.

eminences, which have been identified as floccular recesses (however, not present in all Stegosaurus specimens ${ }^{14}$ ), and both taxa have spiked tails, which were very likely proper defensive means ${ }^{49,50}$. Arbour and Currie ${ }^{2}$ reported a stepwise acquisition of clubbed tails in ankylosaurids, leading to a handle first (interlocking vertebrae produce a stiffened tail) and a knob second (fusion of distal-most osteoderms) model. Just like nodosaurids, some earlydiverging ankylosaurids show no handle or knob adaptations ${ }^{2}$. Only ankylosaurine ankylosaurids show both, a handle and a knob, producing a functional tail $\mathrm{club}^{2}$. It is conspicuous that endocasts of thyreophoran taxa with a formidable weapon on the tail (Stegosaurus, Kentrosaurus, Euoplocephalus and Tarchia; although a tail club has only been referred to Tarchia ${ }^{2,51}$ ) bear a floccular recess as well ${ }^{11,12,39,40}$. In contrast, nodosaurids and early-diverging ankylosaurids neither show a distinct floccular recess ${ }^{13,32,40}$, nor a tail club ${ }^{2}$ for which targeting would have been useful. Nodosaurids bear long spikes around their neck and shoulder ${ }^{3}$ (which likely rather limited their neck mobility ${ }^{42}$ ) in addition to osteoderms with relatively thicker cancellous cores ${ }^{52}$; an involvement in thermoregulation and display has been hypothesized for ankylosaur armor 9 . While ankylosaurids tend to bear armours only with bulky osteoderms, nodosaurids additionally possess proximodistally very elongated elements $^{3,53}$, may producing an armour with a comparably passive protective/offensive utility ${ }^{9}$. This may suggest a more passive defense tactic through simple hunker down behavior in nodosaurids with less reliance on coordination-related (VOR/VCR) neural tissue (in contrast to ${ }^{32}$ ). Regarding the demonstrably well vascularized neurocranium of ankylosaurs ${ }^{6,13}$, the putative hypertrophied cerebellum in endocasts of Hungarosaurus sp. ${ }^{32}$ and Struthiosaurus transylvanicus ${ }^{17}$ may rather represent areas of extensive blood supply and other soft tissues. Possibly, the flocculus independently developed a larger size because of its neurologic involvement ${ }^{54}$ in VOR/ VCR in the actively defending stegosaurs and late-diverging ankylosaurids (ankylosaurines).

The orientation of the lateral semicircular canal as a proxy for head posture is not necessarily straightforward ${ }^{55,56}$. However, our reconstructions suggest a strongly posteroventrally inclined occipital condyle (c. $55^{\circ}$; Figs. 1C, 2B) for S. austriacus when the LSC is horizontally arranged. Hence, this independently supports the findings of Pereda-Suberbiola and Galton ${ }^{17}$, who compared the skull roof and basisphenoid of S. austriacus with Panoplosaurus mirus, signifying a habitually slightly inclined snout in both taxa.

Auditory capacities and sound production. Following the procedure of Walsh et al. ${ }^{34}$, the auditory acuity of S. austriacus seems somewhat superior to that of turtles. Paulina-Carabajal et al. ${ }^{40}$ considered the cochlea 
to be relatively short in the nodosaurid P. campbelli because of the ventrally situated fenestra ovalis, which marks the border of the vestibular system and the cochlea. However, this contrasts with the practice of Walsh et al. ${ }^{34}$, who included the fenestra ovalis in the cochlear duct length. Animals are likely to perceive sounds they are able to produce themselves (Walsh et al. ${ }^{34}$ and references therein). Because ankylosaurids seem to possess longer cochlear ducts than nodosaurids, it has been hypothesized that ankylosaurids had more sophisticated sound producing and perception capabilities in comparison to nodosaurids $\mathrm{s}^{15,40}$. The presence of relatively shorter and less convoluted nasal passages, which are possibly involved in sound production, in the nodosaurid P. mirus, compared to the ankylosaurid E. tutus, potentially supports this interpretation ${ }^{6,30,40,42}$. Nonetheless, the nasal passages of ankylosaurs may have mainly served as adaptation for thermal homeostasis of the brain by vascular tissues shedding excess heat into the nasal passages (being seemingly more efficient in E. tutus than in P. mirus ). $^{6}$. The extremely short cochlear duct of $S$. austriacus (in fact the shortest found in a dinosaur so far) may further support inferior auditory capabilities of nodosaurids in comparison to ankylosaurids.

\section{Conclusions}

Whereas nodosaurids and ankylosaurids were lumbering ${ }^{57,58}$, heavily armoured ${ }^{9,52}$ and low-browsing ${ }^{5}$ animals, mainly relying on large guts (possibly for fermentation) to digest ${ }^{53}$, nodosaurids possibly preferred coastal or fluvial environments ${ }^{4}$ and are suspected for having evolved jaw biomechanics delivering stronger bite forces ${ }^{7,8}$ (potentially for tougher plant material), and the gut content of a nodosaurid hints to a selective feedings style ${ }^{5}$. Furthermore, the combination of a relatively short cochlear duct ${ }^{40}$, the lack of a floccular recess ${ }^{13,17,32,40}$, a short $\mathrm{ASC}^{40}$, less elaborated nasal passages ${ }^{6}$, the obligate absence of a tail club ${ }^{2}$, but thickened osteoderms ${ }^{9,52}$ in nodosaurids indicate different ecological adaptations in comparison to ankylosaurids. Hence, nodosaurids were possibly less reliant on their sense of hearing, applied a less active style of self-defense and, apparently, occupied different ecological niches than ankylosaurids. The new findings of the neuroanatomy of Struthiosaurus austriacus seem to add to this differentiation.

\section{Materials and methods}

The holotype specimen of Struthiosaurus austriacus, IPUW 2349/6, represents an incomplete braincase that is traversed by breakages but not deformed, preserving the posterior part of the skull roof, most of the occipital region and part of the basicranium. It is about $55 \mathrm{~mm}$ in mediolateral width and measures $50 \mathrm{~mm}$ anteroposteriorly and dorsoventrally. Although already described elsewhere ${ }^{16,17,26}$, micro-CT-based neuroanatomical accounts for IPUW 2349/6 have never been made.

We scanned IPUW 2349/6 using the desktop micro-computed tomography device (micro-CT) SkyScan/ Bruker 1173 housed in the Department of Palaeontology, University of Vienna (voltage: $130 \mathrm{kV}$, X-ray tube current: $61 \mu \mathrm{A}$, exposure time: $1249 \mathrm{~ms}$, filter: brass $0.25 \mathrm{~mm}$, voxel size: $0.032904 \mathrm{~mm}$ ). Digital segmentation and measurements were produced utilizing the software Amira (6.1), based on bmp image files, which were exported using DataViewer 1.5.4.0. (Skyscan/Bruker). The micro-CT data were manually segmented to create 3D models, which were mirrored afterwards. The density contrast between the fossil and the sediment within was relatively weak, but whereas the respective cavities were still clearly discernable, it was not possible to distinguish individual bones and sutures of the neurocranium. The photogrammetry models are based on 122 photographs and were created with Agisoft (1.7.2).

\section{Data availability}

The micro-CT slice data, neuroanatomical and photogrammetry models of IPUW 2349/6, are published online, in the repository MorphoSource (Project: Struthiosaurus austriacus-IPUW 2349/6-Schade et al. 2021 neuro anatomy//MorphoSource).

Received: 17 August 2021; Accepted: 6 December 2021

Published online: 07 January 2022

\section{References}

1. Thompson, R. S., Parish, J. C., Maidment, S. C. R. \& Barrett, P. M. Phylogeny of the ankylosaurian dinosaurs (Ornithischia: Thyreophora). J. Syst. Palaeontol. 10(2), 301-312 (2012).

2. Arbour, V. M. \& Currie, P. J. Ankylosaurid dinosaur tail clubs evolved through stepwise acquisition of key features. J. Anat. 227, 514-523. https://doi.org/10.1111/joa.12363 (2015).

3. Brown, C. M. An exceptionally preserved armored dinosaur reveals the morphology and allometry of osteoderms and their horny epidermal coverings. PeerJ 5, e4066. https://doi.org/10.7717/peerj.4066 (2017).

4. Butler, R. J. \& Barrett, P. M. Palaeoenvironmental controls on the distribution of Cretaceous herbivorous dinosaurs. Sci. Nat. 95, 1027-1032 (2008).

5. Brown, C. M. et al. Dietary palaeoecology of an Early Cretaceous armoured dinosaur (Ornithischia; Nodosauridae) based on floral analysis of stomach contents. R. Soc. Open Sci. 7, 200305. https://doi.org/10.1098/rsos.200305 (2020).

6. Bourke, J. M., Porter, W. R. \& Witmer, L. M. Convoluted nasal passages function as efficient heat exchangers in ankylosaurs (Dinosauria: Ornithischia: Thyreophora). PLoS ONE 13, e0207381. https://doi.org/10.1371/journal.pone.0207381 (2018).

7. Mallon, J. C. \& Anderson, J. S. The functional and palaeoecological implications of tooth morphology and wear for the megaherbivorous dinosaurs from the dinosaur park formation (Upper Campanian) of Alberta, Canada. PLoS ONE 9(6), e98605. https:// doi.org/10.1371/journal.pone.0098605 (2014).

8. Ösi, A., Prondvai, E., Mallon, J. \& Bodor, E. R. Diversity and convergences in the evolution of feeding adaptations in ankylosaurs (Dinosauria: Ornithischia). Hist. Biol. 29(4), 539-570. https://doi.org/10.1080/08912963.2016.1208194 (2017).

9. Hayashi, S., Carpenter, K., Scheyer, T. M., Watanabe, M. \& Suzuki, D. Function and evolution of ankylosaur dermal armor. Acta Palaeontol. Pol. 55(2), 213-228 (2010).

10. Norman, D. B. Scelidosaurus harrisonii from the Early Jurassic of Dorset, England: Cranial anatomy. Zool. J. Linn. Soc. 188(1), 1-81. https://doi.org/10.1093/zoolinnean/zlz074 (2019). 
11. Galton, P. M. Endocranial casts of the plated dinosaur Stegosaurus (Upper Jurassic, Western USA): A complete undistorted cast and the original specimens of Othniel Charles Marsh. In The Armored Dinosaurs (ed. Carpenter, K.) 103-129 (Indiana University Press, 2001).

12. Galton, P. M. Skull bones and endocranial casts of stegosaurian dinosaur Kentrosaurus Hennig, 1915 from Upper Jurassic of Tanzania, East Africa. Geol. Palaeontol. 22, 123-143 (1988).

13. Kuzmin, I. et al. The braincase of Bissektipelta archibaldi-new insights into endocranial osteology, vasculature, and paleoneurobiology of ankylosaurian dinosaurs. Biol. Commun. 65(2), 85-156. https://doi.org/10.21638/spbu03.2020.201 (2020).

14. Leahey, L. G., Molnar, R. E., Carpenter, K., Witmer, L. M. \& Salisbury, S. W. Cranial osteology of the ankylosaurian dinosaur formerly known as Minmi sp. (Ornithischia: Thyreophora) from the Lower Cretaceous Allaru Mudstone of Richmond, Queensland, Australia. PeerJ 3, e1475. https://doi.org/10.7717/peerj.1475 (2015).

15. Paulina-Carabajal, A., Lee, Y. N., Kobayashi, Y., Lee, H. J. \& Currie, P. J. Neuroanatomy of the ankylosaurid dinosaurs Tarchia teresae and Talarurus plicatospineus from the Upper Cretaceous of Mongolia, with comments on endocranial variability among ankylosaurs. Palaeogeogr. Palaeoclimatol. Palaeoecol. 494, 135-146. https://doi.org/10.1016/j.palaeo.2017.11.030 (2018).

16. Pereda-Suberbiola, X. \& Galton, P. M. On the taxonomic status of the dinosaur Struthiosaurus austriacus Bunzel from the Late Cretaceous of Austria. C. R. Acad. Sci. Paris II 315, 1275-1280 (1992).

17. Pereda-Suberbiola, X. \& Galton, P. M. Revision of the cranial features of the dinosaur Struthiosaurus austriacus Bunzel (Ornithischia: Ankylosauria) from the Late Cretaceous of Europe. Neues Jahrb. Geol. Palaontol. Abh. 191, 173-200 (1994).

18. Pereda-Suberbiola, X. \& Galton, P. M. Reappraisal of the nodosaurid ankylosaur Struthiosaurus austriacus Bunzel from the Upper Cretaceous Gosau Beds of Austria. In The Armored Dinosaurs (ed. Carpenter, K.) 173-210 (Indiana University Press, 2001).

19. Pereda-Suberbiola, X. A revised census of European Late Cretaceous nodosaurids (Ornithischia: Ankylosauria): Last occurrence and possible extinction scenarios. Terra Nova 4, 641-648 (1992).

20. Pereda-Suberbiola, X. Ankylosaurian dinosaur remains from the Upper Cretaceous of Laño (Iberian Peninsula). Est. Mus. Cienc. Nat. de Álava 14(Número especial 1), 273-288 (1999).

21. Pereda-Suberbiola, X., Astibia, H. \& Buffetaut, E. New remains of the armoured dinosaur Struthiosaurus from the Late Cretaceous of the Iberian peninsula (Lafio locality, Basque-Cantabric Basin). Bull. Soc. Géol. Fr. 166, 207-211 (1995).

22. Garcia, G. \& Pereda-Suberbiola, X. A new species of Struthiosaurus (Dinosauria: Ankylosauria) from the upper cretaceous of Villeveyrac (Southern France). J. Vertbr. Paleontol 23(1), 156-165 (2003).

23. Nopcsa, F. Dinosaurierreste aus Siebenbürgen V. Geologica Hungarica, Series Palaeontologica 4, 1-76 (1929).

24. Codrea, V. et al. More than just Nopcsa's Transylvanian dinosaurs: A look outside the Hațeg Basin. Palaeogeogr. Palaeoclimatol. Palaeoecol. 293, 391-405. https://doi.org/10.1016/j.palaeo.2009.10.027 (2010).

25. Ösi, A. \& Prondvai, E. Sympatry of two ankylosaurs (Hungarosaurus and cf. Struthiosaurus) in the Santonian of Hungary. Cretac. Res. 44, 30-38. https://doi.org/10.1016/j.cretres.2013.03.006 (2013).

26. Bunzel, E. Die Reptilfauna der Gosaformation in der Neuen Welt bei Wiener-Neustadt. Abhandlungen der Kaiserlich-Königlichen Geologischen Reichsanstalt. 5, 1-18 (1871).

27. Franzosa, J. \& Rowe, T. Cranial endocast of the Cretaceous theropod dinosaur Acrocanthosaurus atokensis. J. Vertebr. Paleontol. 25, 859-864 (2005).

28. Witmer, L. M. \& Ridgely, R. C. New insights into the brain, braincase, and ear region of tyrannosaurs (Dinosauria, Theropoda), with implications for sensory organization and behavior. Anat. Rec. 292(9), 1266-1296. https://doi.org/10.1002/ar.20983 (2009).

29. Schade, M., Rauhut, O. W. M. \& Evers, S. W. Neuroanatomy of the spinosaurid Irritator challengeri (Dinosauria: Theropoda) indicates potential adaptations for piscivory. Sci. Rep. 10(9259), 1613-1616. https://doi.org/10.1038/s41598-020-66261 (2020).

30. Witmer, L. M., Ridgely, R. C., Dufeau, D. L. \& Semones, M. C. Using CT to peer into the past: 3D visualization of the brain and ear regions of birds, crocodiles, and nonavian dinosaurs. In Anatomical imaging: towards a new morphology (eds Endo, H. \& Frey, R.) 67-87 (Springer, 2008).

31. Evers, S. W. et al. Neurovascular anatomy of the protostegid turtle Rhinochelys pulchriceps and comparisons of membranous and endosseous labyrinth shape in an extant turtle. Zool. J. Linn. Soc. 187, 800-828. https://doi.org/10.1093/zoolinnean/zlz063 (2019).

32. Ösi, A., Pereda Suberbiola, X. \& Földes, T. Partial skull and endocranial cast of the ankylosaurian dinosaur Hungarosaurus from the Late Cretaceous of Hungary: Implications for locomotion. Palaeontol. Electro. 17(1), 18p (2014).

33. Sampson, S. D. \& Witmer, L. M. Craniofacial anatomy of Majungasaurus crenatissimus (Theropoda: Abelisauridae) from the Late Cretaceous of Madagascar. J. Vertebr. Paleontol. 27, 32-104. https://doi.org/10.1671/0272-4634(2007)27[32:CAOMCT]2.0.CO;2 (2007).

34. Walsh, S. A., Barrett, P. M., Milner, A. C., Manley, G. \& Witmer, L. M. Inner ear anatomy is a proxy for deducing auditory capability and behaviour in reptiles and birds. Proc. R. Soc. B 276, 1355-1360 (2009).

35. Porter, W. R. \& Witmer, L. M. Vascular patterns in the heads of dinosaurs: Evidence for blood vessels, sites of thermal exchange, and their role in physiological thermoregulatory strategies. Anat. Rec. 303, 1075-1103. https://doi.org/10.1002/ar.24234 (2019).

36. Benson, R. B. J., Starmer-Jones, E., Close, R. A. \& Walsh, S. A. Comparative analysis of vestibular ecomorphology in birds. J. Anat. 231, 990-1018. https://doi.org/10.1111/joa.12726 (2017).

37. Bronzati, M. et al. Deep evolutionary diversification of semicircular canals in archosaurs. Curr. Biol. 31(12), 2520-2529.e6. https:// doi.org/10.1016/j.cub.2021.03.086 (2021).

38. Hanson, M., Hoffman, E. A., Norell, M. A. \& Bhullar, B. S. The early origin of a birdlike inner ear and the evolution of dinosaurian movement and vocalization. Science 372(6542), 601-609. https://doi.org/10.1126/science.abb4305 (2021).

39. Miyashita, T., Arbour, V. M., Witmer, L. M. \& Currie, P. J. The internal cranial morphology of an armoured dinosaur Euoplocephalus corroborated by X-ray computed tomographic reconstruction. J. Anat. 219, 661-675. https://doi.org/10.1111/j.1469-7580.2011. 01427.x (2011).

40. Paulina-Carabajal, A., Lee, Y. N. \& Jacobs, L. L. Endocranial morphology of the primitive nodosaurid dinosaur Pawpawsaurus campbelli from the Early Cretaceous of North America. PLoS ONE 11, e0150845. https://doi.org/10.1371/journal.pone.0150845 (2016).

41. Spoor, F. \& Thewissen, J. G. M. Comparative and functional anatomy of balance in aquatic mammals. In Sensory Evolution on the Threshold, Adaptations in Secondarily Aquatic Vertebrates (eds Thewissen, J. G. M. \& Nummela, S.) 65-81 (University of California Press, 2008).

42. Sobral, G. \& Müller, J. Archosaurs and their kin: The ruling reptiles. In Evolution of the Vertebrate Ear (eds Clack, J. A. et al.) 285-326 (Springer, 2016).

43. Arbour, V. M. Estimating impact forces of tail club strikes by ankylosaurid dinosaurs. PLoS ONE 4(8), e6738. https://doi.org/10. 1371/journal.pone.0006738 (2009).

44. Park, J. Y. et al. A new ankylosaurid skeleton from the Upper Cretaceous Baruungoyot Formation of Mongolia: Its implications for ankylosaurid postcranial evolution. Sci. Rep. 11, 4101. https://doi.org/10.1038/s41598-021-83568-4 (2021).

45. Witmer, L. M., Chatterjee, S., Franzosa, J. \& Rowe, T. Neuroanatomy of flying reptiles and implications for flight, posture and behaviour. Nature 425, 950-953. https://doi.org/10.1038/nature02048 (2003).

46. Walsh, S. A. et al. Avian cerebellar floccular fossa size is not a proxy for flying ability in birds. PLoS ONE 8(6), e67176. https://doi. org/10.1371/journal.pone.0067176 (2013).

47. Ferreira-Cardoso, S. et al. Floccular fossa size is not a reliable proxy of ecology and behaviour in vertebrates. Sci. Rep. 7(1), 2017. https://doi.org/10.1038/s41598-017-01981-0 (2005). 
48. Ezcurra, M. D. et al. Enigmatic dinosaur precursors bridge the gap to the origin of Pterosauria. Nature 588(7838), 445-449. https:// doi.org/10.1038/s41586-020-3011-4 (2020) (Epub 2020 Dec 9).

49. Carpenter, K., Sanders, F., McWhinney, L. A. \& Wood, L. Evidence for predator-prey relationships: examples for Allosaurus and Stegosaurus. In The Carnivorous Dinosaurs (ed. Carpenter, K.) 325-350 (Indiana University Press, 2005).

50. Mallison, H. CAD assessment of the posture and range of motion of Kentrosaurus aethiopicus HENNIG 1915. Swiss. J. Geosci. 103, 211-233. https://doi.org/10.1007/s00015-010-0024-2 (2010).

51. Arbour, V. M., Lech-Hernes, N. L., Guldberg, T. E., Hurum, J. H. \& Currie, P. J. An ankylosaurid dinosaur from Mongolia with in situ armour and keratinous scale impressions. Acta Palaeontol. Pol. 58(1), 55-64. https://doi.org/10.4202/app.2011.0081 (2013).

52. Scheyer, T. M. \& Sander, P. M. Histology of ankylosaur osteoderms: Implications for systematics and function. J. Vertebr. Paleontol. 24, 874-893 (2004).

53. Carpenter, K. Ankylosauria. In The Complete Dinosaur 2nd edn (eds Brett-Surman, M. K. et al.) 505-526 (Indiana University Press, 2012).

54. Jerison, H. J. Evolution of the brain and intelligence 482 (Academic Press, 1973).

55. Marugan-Lobon, J., Chiappe, L. M. \& Farke, A. A. The variability of inner ear orientation in saurischian dinosaurs: Testing the use of semicircular canals as a reference system for comparative anatomy. PeerJ 1, e124 (2013).

56. Benoit, J. et al. A test of the lateral semicircular canal correlation to head posture, diet and other biological traits in "ungulate" mammals. Sci. Rep. 10, 19602. https://doi.org/10.1038/s41598-020-76757-0 (2020).

57. Coombs, W. P. Jr. Forelimb muscles of the Ankylosauria (Reptilia, Ornithischia). J. Paleontol. 52, $642-657$ (1978).

58. Maidment, S. C. R. \& Barrett, P. M. Osteological correlates for quadrupedality in ornithischian dinosaurs. Acta Palaeontol. Pol. 59(1), 53-70 (2014).

\section{Acknowledgements}

We thank Marie Hörnig, Jakob Krieger, Steffen Harzsch and Ingelore Hinz-Schallreuter (all University of Greifswald, Germany), together with Benjamin Englich (Dinosaurierpark Münchehagen, Germany) and Fabrizio De Rossi (University of Vienna, Austria) for their support. We very much appreciate the dedicated and focused advisory opinions of Susannah Maidment and an anonymous reviewer, which improved an earlier version of the manuscript, as well as Tom Langen for editorial processing of this article. M.S. is supported by the Bogislaw scholarship, University of Greifswald. Open access funding provided by the University of Vienna.

\section{Author contributions}

M.S., S.S., J.K. and C.P. designed the project. S.S. conducted the CT scans and M.S. segmented the data. M.S. and S.S. prepared the figures. M.S., S.S., J.K. and C.P. interpreted the data and wrote the manuscript. C.K. produced the photogrammetric models.

\section{Competing interests}

The authors declare no competing interests.

\section{Additional information}

Correspondence and requests for materials should be addressed to M.S. or C.P.

Reprints and permissions information is available at www.nature.com/reprints.

Publisher's note Springer Nature remains neutral with regard to jurisdictional claims in published maps and institutional affiliations.

(c) Open Access This article is licensed under a Creative Commons Attribution 4.0 International

License, which permits use, sharing, adaptation, distribution and reproduction in any medium or format, as long as you give appropriate credit to the original author(s) and the source, provide a link to the Creative Commons licence, and indicate if changes were made. The images or other third party material in this article are included in the article's Creative Commons licence, unless indicated otherwise in a credit line to the material. If material is not included in the article's Creative Commons licence and your intended use is not permitted by statutory regulation or exceeds the permitted use, you will need to obtain permission directly from the copyright holder. To view a copy of this licence, visit http://creativecommons.org/licenses/by/4.0/.

(c) The Author(s) 2022 